Conclusions The data from this study recorded the prevalence of high-risk HPV genotypes. Sociodemographic characteristics related to sexual health were relevance significantly in women without cytological abnormalities. These results may be useful to future epidemiological surveillance reports and evaluation of new clinical and subclinical cases of cervical intraepithelial neoplasia and genital warts.

Support: Coordenação de Aperfeiçoamento de Pessoal de Nivel Superior (CAPES)/Programa Brasil Sem Miséria; Conselho Nacional de Desenvolvimento Científico e Tecnológico (CNPq)

\section{LB3.247 FACTORS ASSOCIATED WITH THE ABANDONMENT OF THE ANTIRETROVIRAL TREATMENT AMONG PATIENTS WITH HIVIAIDS ACCOMPANIED THE CENTRE OF REFERENCE STD/AIDS OF CAMPINASSP, BRAZIL}

${ }^{1}$ Raquel Tozzo De Lima, ${ }^{2}$ Márcio Cristiano De Melo, ${ }^{2}$ Maria Rita Donalísio. ${ }^{1}$ City Hall of Campinas, Referral Centre for Std/Aids, Campinas - SP, Brazil; ${ }^{2}$ Faculty of Medical Sciences - State University of Campinas, Department of Public Health, Campinas - SP, Brazil

\subsection{6/sextrans-2017-053264.482}

Introduction The objective of the study was to identify and analyse the sociodemographic, epidemiological, clinical and laboratory factors associated with treatment abandonment and follow-up among PLHA.

Methods This is a retrospective case control study of a sample of medical records of adult patients with HIV who use a referral centre for STD in municipality of Campinas-SP, Brazil. Cases were patients without antiretroviral withdrawal at the pharmacy for 365 days or more, obtained from the Logistic Control System of Medicines in July 2015, $(n=50)$. For controls group, 100 adult patients adhering to ART were randomly selected for 365, and 58 meet the criteria, from March 2014 to March 2015. After the univariate analysis of the data, a multiple logistic regression model was adjusted considering cases, controls and covariates of interest.

Results The variables that favoured the abandonment of follow-up and treatment were: black/brown referred colour $(\mathrm{OR}=6.54, \quad 95 \% \mathrm{CI}: \quad 1.48-28.88)$, being unemployed $(\mathrm{OR}=6.38, \quad 95 \% \mathrm{CI}: \quad 1.61-25.35)$, being heterosexual $(\mathrm{OR}=6.94, \quad 95 \% \mathrm{CI}: \quad 1.18$ 40.97) and being smoker $(\mathrm{OR}=10.39$, 95\% CI: 2.59-41.69). Higher education $(\mathrm{OR}=0.05,95 \% \mathrm{CI}: 0.00-0.46)$ and to be attended by multi professional team $(\mathrm{OR}=0.19,95 \% \mathrm{CI}: 0.04-0.96)$ appeared as protective factors of abandonment.

Conclusion The abandonment of follow-up and treatment among the patients from STD/HIV referred centre in Campinas were positively associated with socioeconomic precariousness. Access to the multiprofessional team was a protective factor to prevent abandonment of ART in the study population.

\section{LB3.248 FACTORS ASSOCIATED WITH SURVIVAL OF PATIENTS COINFECTED WITH AIDS AND HCV}

Márcio Cristiano de Melo, Maria Rita Donalisio. Faculty of Medical Science State University of Campinas, Department of Public Health, Campinas - SP, Brazil

10.1136/sextrans-2017-053264.483
Introduction The objective of this study was to analyse the survival of patients with coinfection AIDS/HCV according to sociodemographic, epidemiological, clinical, and the utilisation of health services in the South and Southeast of Brazil.

Methods This is a retrospective cohort study. The sample of medical records of individuals older than 13 years diagnosed with AIDS, reported in the SINAN in 1998 and 1999 with follow-up of 10 years.

Results Of the 2091 cases of AIDS in over 13 years studied, $307(14,7 \%)$ were diagnosed with Hepatitis $\mathrm{C}$ and 223 (72.6\%) were male. After analysis of the survival curves by KaplanMeier method a multiple regression model of Cox was adjusted. The variables positively associated with longer survival were: being female ( $\mathrm{HR}=0.68 \mathrm{CI} 95 \% \%$ : 0.510 .83$)$, higher education ( $\mathrm{HR}=0.51 \mathrm{CI} 95 \% \%$ : $0.35-0.76)$, CD4 diagnostic criteria $(\mathrm{HR}=0.57 \mathrm{CI} 95 \% \%$ : $0.46-0.72)$. Variables associated negatively with survival were: age $\geq 60$ years $(\mathrm{HR}=2.47 \mathrm{CI95 \%} \%$ : 1.38-4.26), irregular use of ARV $(\mathrm{HR}=8,71 \mathrm{CI} 95 \% \%$ : 6.72-11.27), not having consulted with other health professionals than physician and/or nurse $(\mathrm{HR}=1.25 \mathrm{CI95 \%} \%$ : 1.031,53), coinfection AIDS-tuberculosis (HR 1.42 CI95\%: 1.17-1.71) and one or more opportunistic infections $\quad(\mathrm{HR}=1,37$ 95\% CI: 1.21-1.55). Patients with AIDSHCV coinfection had lower survival than those without coinfection. The cumulative survival in accordance with the KaplanMeier method was $82 \%$ in non coinfected and $78 \%$ in coinfected after 60 months of the diagnosis of AIDS. However coinfection AIDS/HCV didn't remain in the final model as a predictor of survival.

Conclusion Despite the progress in HIV treatment and control, some challenges remain, including overcoming inequalities, early diagnosis, and ensuring the availability and adherence to treatment with drug combination with lower toxicity and ease intake. AIDS and Hepatitis $\mathrm{C}$ are two chronic diseases can be analysed as markers of quality of care and AIDS in Brazil.

\section{LB3.249 HIVIAIDS AND TUBERCULOSIS ON TRANSVESTITES AND TRANSGENDERS (MTFS) IN SÃO PAULO, BRAZIL}

${ }^{1}$ Ferreira-Jr S, ${ }^{2}$ Francisco PMSB, ${ }^{2}$ Melo MCD, ${ }^{1}$ Nogueira PA. ${ }^{1}$ Faculty of Public Health University of São Paulo, Brazil; ${ }^{2}$ Department of Collective Health - University of São Paulo, Brazil

\subsection{6/sextrans-2017-053264.484}

Introduction To know the conditions of life and health, to identify differences between transvestites and $\mathrm{MtFs}$, and to verify the proportion of cases of HIV-AIDS and tuberculosis in these subgroups.

Methods A cross-sectional study realised in São Paulo city, Brazil, in 2014, with the application of a KAP questionnaire (Knowledge, Attitudes and Practices) to a convenience sample of 124 individuals (58 transvestites and $66 \mathrm{MtFs}$ ) aged $\geq 18$ years. Comparisons between the percent distributions of the groups were performed using the Pearson chi-square test or Fisher's exact test, considering a significance level of 5\%.

Results The mean age of all respondents was 32.2 years $(\mathrm{SD}=9.9$ years). Statistical differences were observed between groups regarding prostitution and passage through prisons 
$(p<0.001)$. The use of alcohol and drugs was high in both groups, and cocaine and crack were the most commonly reported drugs. All transvestites and $80 \%$ of MtFs referred syphilis treatment. About $36 \%$ of transvestites and $22.7 \%$ of $\mathrm{MtFs}$ were HIV+ $(\mathrm{p}=0.099)$. They had already performed treatment for tuberculosis, $25.9 \%$ of transvestites and $9.1 \%$ of MtFs ( $p=0.096)$. HIV-AIDS-tuberculosis co-infection was observed in $17.2 \%$ of transvestites and $6.1 \%$ of $\mathrm{MtFs}$.

Conclusion The results indicate that the living and health conditions of this population are marked by their vulnerability to HIV-AIDS and co-infection with tuberculosis. The invisibility of this group in official health data compromises the control of these diseases in this population. Also, the dichotomies observed between transvestites and MtFs should be considered in the planning of preventive actions and future studies.

\section{LB3.250 A COMPARATIVE ANALYSIS OF COSTS OF SINGLE AND DUAL RAPID HIV AND SYPHILIS DIAGNOSTICS: RESULTS FROM A RANDOMISED CONTROL TRIAL IN COLOMBIA}

\begin{abstract}
${ }^{1}$ Carol Dayo Obure, ${ }^{2}$ Hernando Gaitan, ${ }^{2}$ Ricardo Losada Saenz, ${ }^{2}$ Lina Gonzalez, ${ }^{2}$ Edith Angel-Muller, ${ }^{3}$ Maura Laverty, ${ }^{4}$ Freddy Perez. ${ }^{1}$ London School of Hygiene and Triopical Medicine, London, UK; ${ }^{2}$ Universidad Nacional de Colombia, Bogota - Colombia; ${ }^{3}$ World Health Organisation, Geneva, Switzerland; ${ }^{4}$ Pan American Health Organisation, Washington DC, USA
\end{abstract}

\subsection{6/sextrans-2017-053264.485}

Introduction HIV and congenital syphilis are major public health burdens contributing to substantial perinatal morbidity and mortality globally. Although studies have reported on the costs and cost effectiveness of rapid diagnostic tests (RDTs) for syphilis screening within antenatal care in a number of resource constrained settings, empirical evidence on country specific cost and estimates of single RDTs compared to dual RDTs for HIV and syphilis are limited.

Methods A cluster randomised control study design was used to compare the incremental costs of two testing algorithms: 1) single RDTs for HIV and syphilis; and 2) dual RDTs for HIV and syphilis, in 12 health facilities in Bogotá and Cali, Colombia. The costs of single HIV and syphilis RDTs and dual HIV and syphilis RDTs were collected from each of the health facilities. The economic costs per woman tested for HIV and syphilis and costs per woman treated for syphilis defined as the total costs required to test and treat one woman for syphilis were estimated.

Results A total of 2214 women were tested in the study facilities. Cost per pregnant woman tested and cost per woman treated for syphilis were $\$ 10.26$ and $\$ 607.99$ respectively in the single RDT arm. For the dual RDTs, the cost per pregnant woman tested for HIV and syphilis and cost per woman treated for syphilis were $\$ 15.89$ and $\$ 1,859.26$ respectively. Overall costs per woman tested for HIV and syphilis and cost per woman treated for syphilis were lower in Cali compared to Bogotá across both intervention arms. Staff costs accounted for the largest proportion of costs while treatment costs comprised less than $1 \%$ of the preventive program.

Conclusion Findings show lower average costs for single RDTs compared to dual RDTs with costs sensitive to personnel costs and the scale of output at the health facilities.

\section{LB3.251 PATIENT REFERRAL ALONE IS NOT AN EFFECTIVE STRATEGY TO CAPTURE PARTNERS OF PATIENTS WITH SEXUALLY TRANSMITTED INFECTIONS IN LOW RESOURCE SETTINGS: A CASE-CONTROL STUDY}

Mache Tsadik. Mekelle University, Mekelle City, Ethiopia

\subsection{6/sextrans-2017-053264.486}

Introduction Partner notification (PN) is a key public health intervention aimed at preventing re-infection and controls the spread of sexually transmitted infections (STIs). However, limited research has been conducted to investigate factors associated with $\mathrm{PN}$ in Ethiopia.

Methods A nested case-control study was undertaken within a cohort of individuals being treated for STI in public health facilities in Ethiopia. Hierarchical binary logistic regression was used to identify socio-demographic, behavioural and psychosocial factors associated with PN.

Results A total of 250 patients on STI treatment who notified their partners (cases) were compared with 185 patients who did not notify their partners (controls). STI patients were less likely to notify their partner if they were single $[\mathrm{AOR}=0.33$, 95\% CI: $(0.15-0.73)]$, in casual partnership [AOR $=0.33,95 \%$ C:(0.15-73)], not knowledgeable about partner's sexual behaviour $[\mathrm{AOR}=0.43,95 \% \mathrm{CI}:(0.24-0.77)]$, poor knowledge of risk sexual behaviour $[\mathrm{AOR}=0.23,95 \% \mathrm{CI}:(0.12-0.43)]$ and if they had no intention to notify partners $[\mathrm{AOR}=0.19$, 95\% CI: (0.10-0.36)]. The odds of PN were higher among highly educated respondents $[\mathrm{AOR}=5.16$; 95\% CI: $\quad(1.83-$ 14.54)].

Conclusion Capturing STI cases through patient referral partner notification is less likely to be successful among patients who are single and in causal relationship.

\section{LB3.252 PREVALENCE OF SYPHILIS AND FACTORS ASSOCIATED WITH FEMAKE SEX WORKERS IN TERESINA, PIAUÍ}

${ }^{1}$ Braulio Vieira De Sousa Borges, Vanessa Moura Carvalho De Oliveira'; Giselle Mary Ibiapina Brito"; Elucir Gir; Marli Teresinha Gimeniz Galvão3; Rosilane Lima Brito De Magalhães'. 'Universidade Federal do Piauí, Teresina - Pl, Brazil; ' Universidade Federal de São Paulo, Ribeirão Preto - SP, Brazil; ${ }^{3}$ Universidade Federal do Ceará, Fortaleza - CE, Brazil

\subsection{6/sextrans-2017-053264.487}

Introduction Syphilis is a matter of concern for the reason of transmissibility and high magnitude. In the world there is an estimate that there are 357 million new Sexually Transmitted Infections each year, with a high incidence of syphilis with 5.6 million cases. The infection can affect all age groups and both sexes, presenting higher prevalence in populations of greater vulnerability as female sex workers. Therefore, the main goal was to estimate the prevalence of syphilis and associated factors in female sex workers.

Methods Analytical cross-sectional study, part of a macroproject entitled "Outpatient follow-up of HIV and Syphilis in female sex workers", conducted in Teresina, Piauí, Brazil, with 358 female sex workers, developed since August/2016, in follow-up. Approved by a Research Ethics Committee. Participants were recruited by the Respondent-Driven Sampling (RDS) method and the data collected by structured form.

Results Of the total number of participants $(n=358)$, the prevalence of syphilis was $7.5 \%$. Statistical significance was obtained in relation to skin colour (CI 40.84-51.16, $\mathrm{p} \leq 0.001$ ). 